Academic Platform Journal of Engineering and Science

\title{
Kompozit Malzemelerin Tornalanması Esnasında Oluşan Kesme Kuvvetlerinin Optimizasyonu
}

\author{
${ }^{1 * E m i n ~ S a l u r, ~}{ }^{2}$ Abdullah Aslan, ${ }^{3}$ Mustafa Kuntoğlu, ${ }^{4}$ Aydın Güneş, ${ }^{5}$ Ömer Sinan Şahin \\ ${ }^{1}$ Selçuk Üniversitesi, Teknoloji Fakültesi, Metalurji ve Malzeme Mühendisliği Bölümü, Konya, \\ esalur@selcuk.edu.tr iD \\ ${ }^{2}$ Selçuk Üniversitesi, Teknoloji Fakültesi, Makine Mühendisliği Bölümü, Konya, \\ aaslan@selcuk.edu.tr \\ ${ }^{3}$ Selçuk Üniversitesi, Teknoloji Fakültesi, Makine Mühendisliği Bölümü, Konya, \\ mkuntuoglu@selcuk.edu.tr iD \\ ${ }^{4}$ Abdullah Gül Üniversitesi, Mühendislik Fakültesi, Makine Mühendisliği Bölümü, Kayseri, \\ aydin.gunes@agu.edu.tr iD
}

${ }^{5}$ Konya Teknik Üniversitesi, Mühendislik ve Doğa Bilimleri Fakültesi, Makine Mühendisliği Bölümü, Konya, ossahin@ktun.edu.tr iD

Araştırma Makalesi

Geliş Tarihi: 09.10.2019

Kabul Tarihi: 25.01.2020

Öz

Kompozit malzemeler kullanılacağı yere göre tasarlanan ve üretilen malzemelerdir. Dolayısıyla kompozit malzemeler aynı üretim metodu kullanılarak kullanılacağı yere göre farklı üretim parametrelerinde üretilebilir. Farklı üretim parametrelerinde üretilen kompozit malzemeler farklı mekanik özelliklere sahip olacağı için bu durum kompozit malzemelerin işlenebilirlik özelliklerini etkiler. Bu sebeple kompozit malzemelerin işlenmesi esnasında oluşan kesme kuvvetlerinin tespit edilmesi ve optimizasyonu önem arz etmektedir. Bu kapsamda, 3 farklı üretim sicaklığı $\left(350,400\right.$ ve $\left.450^{\circ} \mathrm{C}\right)$ ve basınc1 (480, 640 ve 820 $\mathrm{MPa}$ ) ile 4 farklı karışım oranında (ağ. \%10, ağ. \%20, ăg. \%30, ağ. \%40) üretilen dökme demir (GGG-40) takviyeli ve bronz matrisli (CuSn10) kompozit malzemelerin kuru kesme şartlarında tornalanması esnasında kesme kuvvetlerinin optimizasyonu gerçekleştirilmiştir. Tam faktöriyel tasarım prensibi ile 36 deney yapılmış ve üç eksende kesme kuvvetleri ölçümü alınarak bileşke kesme kuvveti hesabı yapılmıştır. Deneyler esnasında kesme şartları sabit tutulmuştur (kesme hızı=50 m/dak, ilerleme $=0,128 \mathrm{~mm} / \mathrm{dev}$ ve talaş derinliği $=1 \mathrm{~mm}$ ). Varyans analizi (ANOVA) neticesinde bileşke kesme kuvveti üzerine en çok etkisi olan parametrenin \%80 katkı oranıyla birlikte üretim basıncı olduğu tespit edilmiştir.

Anahtar kelimeler: Kompozit malzemeler, tornalama, optimizasyon, kesme kuvvetleri, varyans analizi

\section{Optimization of Cutting Forces During Turning of Composite Materials}

\author{
${ }^{* 1}$ Emin Salur, ${ }^{2}$ Abdullah Aslan, ${ }^{3}$ Mustafa Kuntoğlu, ${ }^{4}$ Aydın Güneş, ${ }^{5}$ Ömer Sinan Şahin \\ ${ }^{1}$ Selçuk University, Faculty of Technology, Department of Metallurgical and Materials Science Engineering, Konya, \\ esalur@selcuk.edu.tr \\ ${ }^{2}$ Selçuk University, Faculty of Technology, Department of Mechanical Engineering, Konya, \\ aaslan@selcuk.edu.tr \\ ${ }^{3}$ Selçuk University, Faculty of Technology, Department of Mechanical Engineering, Konya, \\ mkuntuoglu@selcuk.edu.tr \\ ${ }^{4}$ Abdullah Gül University, Faculty of Engineering, Department of Mechanical Engineering, Kayseri, \\ aydin.gunes@agu.edu.tr
}

${ }^{5}$ Konya Technical University, Faculty of Engineering and Natural Sciences, Department of Mechanical Engineering, Konya, ossahin@ktun.edu.tr

\begin{abstract}
Composites are the type of materials designed and produced according to their usage area. Therefore, composite materials can be produced in accordance with the usage area using the same production method. This situation affects the machinability
\end{abstract}


properties of composites, owing to the fact that different production parameters cause different mechanical properties. For this reason, it is important that the determination and optimization of cutting forces during machining of composite materials. In this context, the optimization of cutting forces of bronze matrix (CuSn10) composites which are reinforced with cast iron (GGG-40) produced using 3 different production temperatures $\left(350,400\right.$ and $\left.450^{\circ} \mathrm{C}\right)$ and pressure $(480,640$ and $820 \mathrm{MPa})$ and $4 \mathrm{different}$ reinforcement (wt. \%10, wt. \%20, wt. \%30, wt. \%40) during dry turning. Full factorial design based 36 experiments were performed and resultant force calculation was carried out with measurement of cutting forces in 3 axes. During experiments cutting conditions were kept constant (cutting speed $=50 \mathrm{~m} / \mathrm{min}$, feed rate $=0,128 \mathrm{~mm} / \mathrm{rev}$ and depth of cut $=1 \mathrm{~mm}$ ). As a result of analysis of variance (ANOVA), it was found that the parameter which has the most effect on the cutting forces is the production pressure with $80 \%$ contribution rate.

Keywords: Composite materials, turning, optimization, cutting forces, analysis of variance

\section{GİRIŞ}

Kompozit malzemeler, kullanılacağı ortama göre tasarlanıp üretilebilmesi sebebiyle endüstriyel uygulamalarda sıç̧a kullanılmaktadır [1, 2]. Matris ve takviye malzemesi olarak iki temel bileşenden oluşan kompozit malzemeler, matris yapısına göre, polimer matris, seramik matris ve metal matrisli kompozitler olarak sinıflandirılırlar [3, 4]. Metal matrisli kompozit malzemeler (MMK), yüksek tokluk ve mukavemet sağlamaları, kullanılan matris ve takviye malzemesine bağlı olarak sıra dışı 1sıl ve elektriksel özellikleri, biçimlendirilebilme özellikleri sebebiyle birçok uygulamada tercih edilir [5]. Metal matrisli kompozit malzemeler, haddeleme [6], sicak ekstrüzyon [7, 8], , soğuk presleme [9], sicak presleme [10, 11], yüksek sicaklıkta burulma [12], in situ [13] gibi yöntemlerle üretilebilirler. Yapılan literatür incelemesinde, bronz [14], pirinç [15], alüminyum [16, 17], magnezyum [18] malzemelerinin kompozit malzeme üretiminde sıkça kullanıldığı görülmektedir. Metal matrisli kompozit malzemelerin darbe [19], basma [14], eğilme [11], sertlik ve gözeneklilik [14], gibi mekanik özelliklerinin yanı sıra işılenebilirlik özellikleri $[20,21]$ de oldukça önemlidir. Yapılan literatür incelemesinde, alüminyum [22], titanyum [23], magnezyum [24] malzemeleri ile üretilen MMK malzemelerin ve seramik takviyeli [25, 26] MMK malzemelerin işleme parametreleri ile alakalı sonuçların rapor edildiği tespit edilmiştir.

Kompozit malzemelerin işlenebilirlik özellikleri incelenirken, genellikle malzemenin üretim parametreleri (üretim sıcaklığı, basıncı, karışım oranı) sabit tutulmuş ve işleme parametreleri (kesme ve ilerleme hızı) değişken hale getirilerek işleme parametrelerinin etkisi incelenmiştir. Bu durum kullanılacağı yere göre farklı parametrelerde üretilen kompozit malzemelerin işlenebilirlik özelliklerini belirlemekte yeterli değildir. Örneğin bir malzeme, sadece bir üretim parametresini değiştirerek yüksek mukavemetli bir yatak malzemesinde düşük mukavemetli ve yüksek gözenekli bir filtre malzemesine dönüşebilir [14]. Bu sebeple üretim parametrelerinin kesme kuvvetlerine etkisini belirlemek oldukça önemlidir. Üretim parametrelerinin etkilerinin belirlenebilmesi için istatistiksel yaklaşımlar [27, 28] ve tahmin araçları [29, 30] kullanılmaktadır.

Metal matrisli kompozit malzemelerin kullanılacağ yere ve şartlara göre tasarlanması sürecinde seçilen alaşım elementleri, takviye malzemesi ve takviye malzemesi oran1, ileri imalat sürecinde malzemenin işlenebilirliğini doğrudan etkilemektedir. Talaşlı imalat işlemlerinde iş parçası olarak kullanılan malzemenin içerisindeki düzensizlikler ve sert parçacıklar, işlemin süreksizliğine, kesici takım aşınmalarına ve yüzey kalitesinin bozulmasına neden olmaktadır. MMK malzemelere belirli özellikler kazandırmak için kullanılan takviye elemanları, işleme karakteristiğini etkilemekte ve kesme bölgesinde anlık değişimler meydana getirmektedir. Özellikle kesici takım ve iş parçası temas alanının kesme işlemi süresince değişmeler göstermesi kesme kuvvetlerinin ve kesici takıma gelen yükün anlık olarak değişmesi sonucunu doğurmaktadır. Değişken yük, yüksek sıcaklık ve basıncın da etkisiyle kesici ucun ömrünü erken tamamlamasına, iş parçasının düşük kaliteli olmasına yol açar [31]. Bu faktörler göz önüne alındığında MMK malzemelerin işlenmesinde kesme kuvvetlerinin takibi ve sonuçlarının değerlendirilmesi kaçınılmaz olmaktadır.

Geçmişte, çeşitli kompozit malzemelerin farklı talaşlı imalat yöntemleriyle şekillendirilmesi ile ilgili çalışmalar bulunmaktadır. Bunlar, aynı malzemenin farklı kesme şartlarında işlendiği [28, 32-34] ve farklı kompozisyon oranlarında ve farklı kesme şartlarında [35-38] işlendiği çalışmalar olarak iki grupta incelenebilir. $\mathrm{Bu}$ çalışmalar dikkate alındığında literatürde bir eksiklik görülmüş ve bu eksiklik doğrultusunda deneysel ve istatistiksel analize dayanan bir çalışmanın yapılması uygun görülmüştür.

Bu çalışmada farklı üretim şartları altında üretimi yapılan 36 adet metal matrisli kompozit malzeme, sabit kesme parametrelerinde tornalanmış ve tornalama esnasında oluşan kesme kuvvetleri dinamometre yardımıyla ölçülmüştür. 3 eksende ölçümü yapılan kesme kuvvetleri hesaplanarak bileşke kesme kuvveti bulunmuştur. Malzemelerin üretim parametreleri olan basınç, sıcaklık ve karışım oranının kesme kuvvetleri üzerindeki etkileri istatistiksel analiz ile değerlendirilmiştir.

\section{MATERYAL VE METOT}

\section{1. Üretim ve Tornalama}

$\mathrm{Bu}$ çalışmada kullanılan metal matrisli kompozit malzemelerin üretimi $[14,39]$ literatürde yer alan çalışmalarda detaylı bir şekilde anlatılmaktadır. 1 ve $2 \mathrm{~mm}$ boyutları arasındaki bronz ve dökme demir talaşları 350, 
400, $450{ }^{\circ} \mathrm{C}$ sicaklıkta 480, 640, $820 \mathrm{MPa}$ basınçta sicak presleme yöntemiyle birleştirilmektedir. Bronz matris içerisindeki takviye dökme demir oranı ise ağ. \%10, 20, 30 ve 40'tır. Deneysel tasarımda kullanılan faktörler ve faktör seviyeleri Tablo 1'de gösterilmiştir. Sicak presleme sonrasında kalıptan çıkarılan silindirik numuneler Tablo 2'de gösterilen şartlarda tornalanmaktadır. Her bir deney için bir adet numune kullanılmış ve ayrı bir kesici uç ile tornalama yapılmıştır. Tornalama esnasında oluşan kesme kuvvetleri (Fc, Ff, Fr) dinamometre ile ölçülerek bileşkeleri alınmıştır (Fb). Deneyde kullanılan TELC markalı dinamometre saniyede 10 veri ölçebilmekte ve doğrudan bilgisayara veri aktarabilmektedir. Kompozit malzemelerin üretimi ve tornalanması Şekil 1 de gösterilmektedir.

Tablo 1. Faktörler ve Faktör Seviyeleri

\begin{tabular}{llllll}
\hline Sembol & Parametreler & Seviye 1 & Seviye 2 & Seviye 3 & Seviye 4 \\
\hline B & Basınç (MPa) & 480 & 640 & 820 & - \\
S & Sicaklık $\left({ }^{\circ}\right.$ C) & 350 & 400 & 450 & - \\
K & Karışım Oranı (ağ. \%) & 10 & 20 & 30 & 40 \\
\hline
\end{tabular}
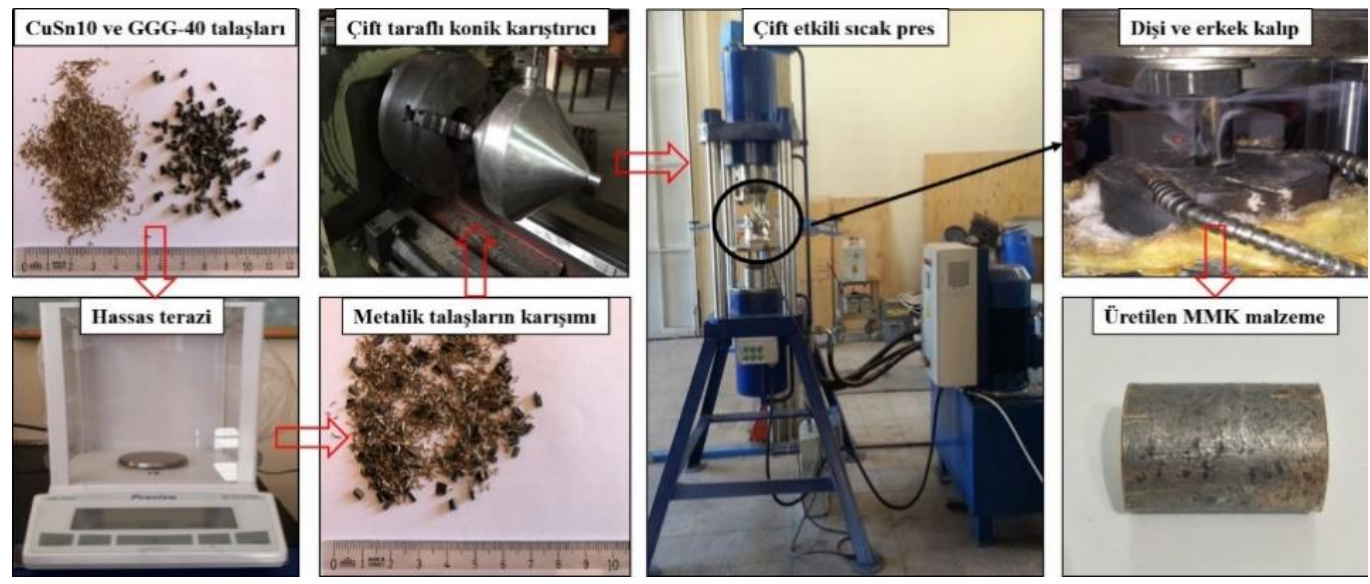

(a)

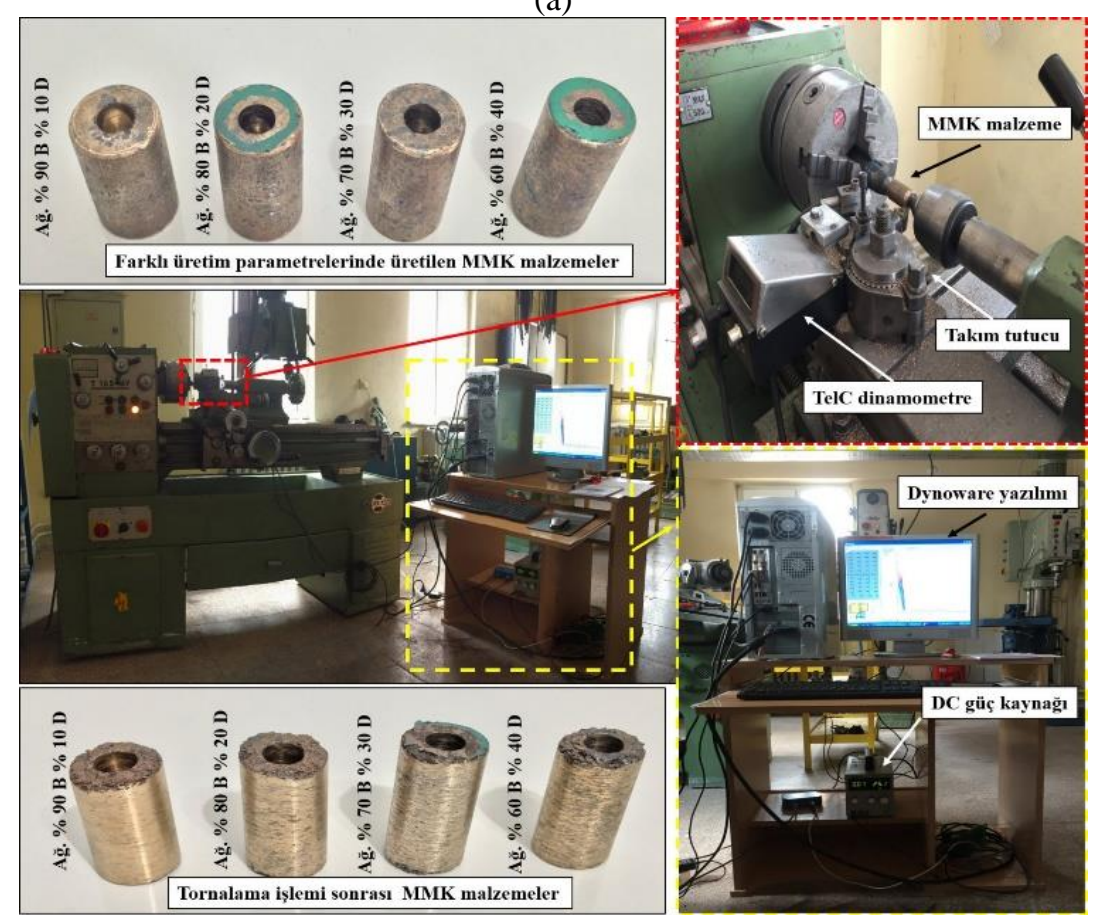

(b)

Şekil 1. MMK malzemelerin (a) üretimi ve (b) tornalanması. 
Tablo 2. Tornalamada Deneysel Şartlar

\begin{tabular}{ll}
\hline Malzeme & Özellikler \\
\hline Takım Tezgâhı & T-165 MF Üniversal Torna \\
Kesici Takım & TCMT 16T304 - Böhler \\
Kesici Takım Geometrisi & Yaklaşma Açısı: $60^{\circ}$ \\
Kesici Takım Tutucu & R/L $14002016-$ Takımsaş \\
Kesme Hızı & $50 \mathrm{~m} / \mathrm{dak}$ \\
İlerleme & $0,128 \mathrm{~mm} / \mathrm{dev}$ \\
Talaş Derinliği & $1 \mathrm{~mm}$ \\
Kesme Sıvısı & Yok \\
\hline
\end{tabular}

\subsection{Varyans Analizi (ANOVA)}

Dökme demir takviyeli bronz matrisli kompozit malzemelerin üretim parametrelerinin kesme kuvvetleri üzerine etkisini incelemek için "Minitab 16.0" yazılımı kullanılarak varyans analizi yapılmıştır. Analiz için basınç, sıcaklık ve karışım oranı bağımsız değişkenler olarak seçilmiştir. Dinamometre ile ölçümü yapılan üç eksendeki kesme kuvvetlerinden yola çıkarak bileşke kesme kuvveti hesaplanmıştır. Bileşke kesme kuvveti bağımlı değişken olarak belirlenmiş ve tam faktöriyel tasarım ilkesine göre 36 deneyin istatistiksel analizi yapılmıştır. 3'er adet basınç ve sıcaklık değerinin yanı sıra 4 adet karışım oranı istatistiksel olarak düzenlenmiş ve Minitab programında tanımlanmıştır.

İstatistiksel analiz, Taguchi deney tasarımına bağlı olarak yapılmış ve sinyal-gürültü oranları da hesaplanarak optimizasyon yapılmıştır. Taguchi yaklaşımı, sinyal-gürültü oranının yanı sıra ortogonal diziler de içeren, bu sayede deney sayısını ve gürültü faktörlerinin etkisini azaltmayı amaçlayan bir tasarımdır. Taguchi tasarımında bulunan 4 amaç fonksiyonu arasından "küçük olan iyidir" (smaller is better) prensibine dayanan yaklaşım tercih edilmiştir. Bunun nedeni tornalama esnasında kesici takım üzerine gelen kesme kuvvetlerinin mümkün oldukça küçük olmasının istenmesidir. $\mathrm{Bu}$ yaklaşım için kullanılan matematiksel formül denklem 1'de verilmiştir. Denklemde y her deneydeki üretim parametrelerinin kareleri toplamını verirken, $\mathrm{n}$ ise toplam parametre sayısını ifade etmektedir.

$\mathrm{S} / \mathrm{N}=-10 \log 1 / \mathrm{n}\left(\Sigma y^{2}\right)$

Sonuç olarak basınç, sıcaklık ve karışım oranından oluşan girdi parametrelerinden her birinin kesme kuvvetleri üzerindeki etkisi veya katkı oranları bulunmuştur. Ayrıca her girdi parametresinin en küçük kesme kuvvetini verecek seviyesi de tespit edilerek kesme kuvveti optimizasyonu yapılmıştır.

\section{BULGULAR VE TARTIŞMA}

Tornalama işleminde, talaş kaldırırken kesici takım ve iş parçasının birbirine göre bağıl hareket etmesi esnasında kesici takımın ilerleme ekseninde (Ff) bir kuvvet meydana gelir. Bu kuvvete dik iki eksen üzerinde ise, kesici takımı tezgâhtan dışarı itmeye zorlayan (Fp) ve aşağı doğru bastıran esas kesme kuvveti $(\mathrm{Fc})$ oluşmaktadır. Meydana gelen bu kuvvetler, takım aşınması, kesici uçta 1sı oluşumu, titreşimler ve parça kalitesi gibi birçok faktör üzerinde etkili olmaktadır. Kesme işleminin çok küçük fakat yüksek hızlar ve basıncın etkili olduğu bir alanda gerçekleşmesi kesme kuvvetlerinde kısa sürede çok hızlı değişimlerin oluşmasına neden olmaktadır. Bu bağlamda tornalama dinamometresi kesme bölgesinin hemen altında olması ve uzama ölçerli (strain gage) yaklaşımla ölçme yapması sebebi ile güvenilir ve anlık bilgi akışı sağlamaktadır. MMK malzemelerin işlenmesi esnasında kesme kuvvetlerinin takip edilmesi, üretim parametrelerinin malzeme yapısını nasıl etkilediği konusunda önemli sonuçların belirlenmesini sağlamıştır. Böylece, kesme kuvvetlerinde meydana gelen değişimlerin üretim parametrelerine bağlı sebepleri anlaşılmış olacaktır. Üretilen MMK malzeme yapısı anizotropik olduğu için işleme esnasında oluşan tüm kuvvetlerin etkisini değerlendirebilmek adına üç eksendeki kuvvetlerin bileşkesi alınmıştır. Bileşke kuvvet hesabı aşağıdaki denklemden faydalanılarak yapılmıştır.

$\mathrm{Fb}=\sqrt{\mathrm{Fc}^{2}+\mathrm{Ff}^{2}+\mathrm{Fp}^{2}}$

Tablo 3'te tam faktöriyel tasarım ilkesine göre düzenlenmiş ve içerisinde deneysel tasarımın bağımsız değişkenleri olan basınç, sıcaklık ve karışım oranı ile bağımlı değişkenleri olan kesme kuvveti bileşenleri ve bileşke kesme kuvveti bulunmaktadır. Ayrıca, her deney için bileşke kesme kuvvetine ait sinyal-gürültü oranları da hesaplanmıştır. Buna göre en düşük bileşke kesme kuvvetini veren deneysel şartlar $\mathrm{B} 3$ ve S3 değerlerinin bulunduğu karışım oranlarında elde edilmektedir. Hem sinyal gürültü oranları hem de bileşke kesme kuvveti değerleri incelendiğinde sonuçların birbiri ile uyumlu olduğu görülmektedir.

Sıcak presleme ile üretim tekniğinde sertlik dağılımını etkileyen en önemli parametre üretim basıncı, mekanik kilitlenme (dökme demir talaşlarının bronz talaşları tarafından kaplanması) mekanizmasını etkileyen en önemli parametre ise sıcaklıktır [39]. Şekil 2'de farklı üretim şartları kombinasyonlarında bileşke kesme kuvvetinin değişimi görülmektedir.

Şekil 2a'da yüksek basınç değerlerinde sıcaklık artışı ile bileşke kesme kuvvetinin azaldığ , basınç değeri düştükçe sıcaklığın artışı ile bileşke kesme kuvvetinin arttığı görülmektedir. 
Hem üretim basıncı hem de üretim sıcaklığının yüksek olması, bronz talaşlarının aşırı plastik deformasyon göstermesine ve mukavemetinin düşmesine neden olmaktadır [4]. Bu durum mekanik kilitlenme mekanizmasını olumsuz etkileyerek daha kolay işlenmesine diğer bir deyişle kuvvetin azalmasına neden olmaktadır. Basınç değeri düştüğünde ise plastik deformasyon sadece sıcaklığın kontrolünde gerçekleştiği için daha etkili bir birleşme oluşur ve işleme kuvveti artar [21].

Şekil 2b'de yüksek basınç değerlerinde karışım oranının artışı ile bileşke kesme kuvvetinin arttığ ile birlikte karışım oranındaki artışın bileşke kesme kuvvetini azalttığı görülmektedir. Bu durum, bronza kıyasla daha sert olan dökme demir talaşlarının oranın artması sebebiyle kompozit malzemenin yapısal bütünlügüünün (mekanik kilitlenmenin) sağlanabilmesi için daha fazla basınca ihtiyaç duymasından kaynaklanmaktadır. Aslan ve ark. [39] tarafından yapılan çalışmada düşük basınçlı ve yüksek dökme demir içerikli numunelerde gözeneklilik değerlerinin yüksek çıkması bu durumu destekler niteliktedir.

Şekil 2c'de ise diğer iki grafikten ayrı olarak en düşük ve en yüksek kuvvet değerleri arasındaki farkın oldukça az olduğu görülmektedir. Çünkü yukarıda da belirtildiği gibi sertlik profili üzerindeki en etkili parametre basınçtır. Bu durum Tablo 3'teki katkı oranları ile kıyaslandığında, sıcaklık ve karışım oranının kesme kuvveti üzerinde etkisinin az olması sonucu ile de uyumludur.

Tablo 3. Tam Faktöriyel Deneysel Tasarım

\begin{tabular}{|c|c|c|c|c|c|c|c|c|}
\hline \multirow{3}{*}{$\begin{array}{l}\text { Deney } \\
\text { No }\end{array}$} & \multicolumn{4}{|c|}{ Bağımsız Değişkenler } & \multicolumn{4}{|c|}{ Bağımlı Değişkenler } \\
\hline & \multirow{2}{*}{$\begin{array}{l}\text { Basınç } \\
\text { B (MPa) }\end{array}$} & \multirow{2}{*}{$\begin{array}{l}\text { Sicaklık } \\
\mathbf{S}\left({ }^{\circ} \mathbf{C}\right)\end{array}$} & \multicolumn{2}{|c|}{ Karışım Oranı } & \multicolumn{4}{|c|}{ Kesme Kuvvetleri } \\
\hline & & & K (ağ. \%) & Fc $(N)$ & $F f(N)$ & Fp (N) & Fb $(\mathbf{N})$ & Fb için $S / N$ oranı \\
\hline 1 & 480 & 350 & 10 & 118,86 & 131,20 & 217,36 & 280,33 & $-48,9536$ \\
\hline 2 & 480 & 350 & 20 & 118,50 & 138,64 & 195,97 & 267,71 & $-48,5534$ \\
\hline 3 & 480 & 350 & 30 & 133,00 & 148,97 & 191,16 & 276,42 & $-48,8327$ \\
\hline 4 & 480 & 350 & 40 & 118,66 & 97,49 & 127,92 & 199,87 & $-46,0152$ \\
\hline 5 & 480 & 400 & 10 & 141,83 & 165,11 & 247,16 & 329,34 & $-50,3530$ \\
\hline 6 & 480 & 400 & 20 & 133,97 & 156,72 & 210,76 & 394,83 & $-49,3917$ \\
\hline 7 & 480 & 400 & 30 & 136,39 & 142,19 & 199,68 & 280,52 & $-48,9594$ \\
\hline 8 & 480 & 400 & 40 & 136,76 & 120,85 & 162,37 & 244,28 & $-47,7580$ \\
\hline 9 & 480 & 450 & 10 & 128,59 & 137,16 & 192,60 & 269,15 & $-48,6002$ \\
\hline 10 & 480 & 450 & 20 & 136,79 & 144,79 & 206,88 & 287,19 & $-49,1635$ \\
\hline 11 & 480 & 450 & 30 & 136,68 & 131,46 & 175,78 & 258,58 & $-48,2519$ \\
\hline 12 & 480 & 450 & 40 & 140,58 & 127,87 & 162,84 & 250,26 & $-47,9681$ \\
\hline 13 & 640 & 350 & 10 & 110,41 & 138,38 & 180,49 & 252,81 & $-48,0561$ \\
\hline 14 & 640 & 350 & 20 & 121,66 & 133,69 & 179,32 & 254,62 & $-48,1181$ \\
\hline 15 & 640 & 350 & 30 & 105,20 & 93,64 & 131,23 & 192,50 & $-45,6889$ \\
\hline 16 & 640 & 350 & 40 & 127,09 & 114,01 & 145,01 & 224,01 & $-47,0056$ \\
\hline 17 & 640 & 400 & 10 & 110,03 & 122,50 & 135,17 & 213,03 & $-46,5692$ \\
\hline 18 & 640 & 400 & 20 & 114,13 & 119,01 & 137,32 & 214,58 & $-46,6321$ \\
\hline 19 & 640 & 400 & 30 & 118,59 & 113,70 & 115,81 & 201,00 & $-46,0642$ \\
\hline 20 & 640 & 400 & 40 & 125,86 & 121,70 & 133,00 & 219,86 & $-46,8433$ \\
\hline 21 & 640 & 450 & 10 & 107,42 & 100,99 & 135,14 & 200,00 & $-46,0208$ \\
\hline 22 & 640 & 450 & 20 & 110,33 & 106,53 & 123,36 & 196,82 & $-46,8817$ \\
\hline 23 & 640 & 450 & 30 & 113,96 & 115,29 & 128,41 & 206,80 & $-46,3113$ \\
\hline 24 & 640 & 450 & 40 & 113,14 & 94,81 & 116,94 & 188,32 & $-45,4983$ \\
\hline 25 & 820 & 350 & 10 & 95,19 & 86,05 & 82,13 & 152,35 & $-43,6573$ \\
\hline 26 & 820 & 350 & 20 & 102,18 & 98,61 & 96,05 & 171,44 & $-44,6824$ \\
\hline 27 & 820 & 350 & 30 & 92,06 & 77,23 & 78,32 & 143,44 & $-43,1335$ \\
\hline 28 & 820 & 350 & 40 & 107,79 & 90,20 & 87,01 & 165,31 & $-44,3660$ \\
\hline 29 & 820 & 400 & 10 & 92,48 & 65,73 & 52,36 & 124,96 & $-41,9360$ \\
\hline 30 & 820 & 400 & 20 & 91,45 & 64,62 & 30,53 & 116,07 & $-41,2946$ \\
\hline 31 & 820 & 400 & 30 & 101,30 & 71,38 & 63,49 & 139,25 & $-42,8759$ \\
\hline 32 & 820 & 400 & 40 & 105,25 & 71,18 & 61,50 & 141,16 & $-42,9945$ \\
\hline 33 & 820 & 450 & 10 & 74,11 & 39,76 & 16,74 & 85,75 & $-38,6655$ \\
\hline 34 & 820 & 450 & 20 & 73,26 & 42,09 & 19,99 & 86,83 & $-38,7736$ \\
\hline 35 & 820 & 450 & 30 & 81,27 & 42,09 & 23,41 & 94,47 & $-39,5065$ \\
\hline 36 & 820 & 450 & 40 & 91,85 & 52,47 & 42,57 & 114,03 & $-41,1407$ \\
\hline
\end{tabular}



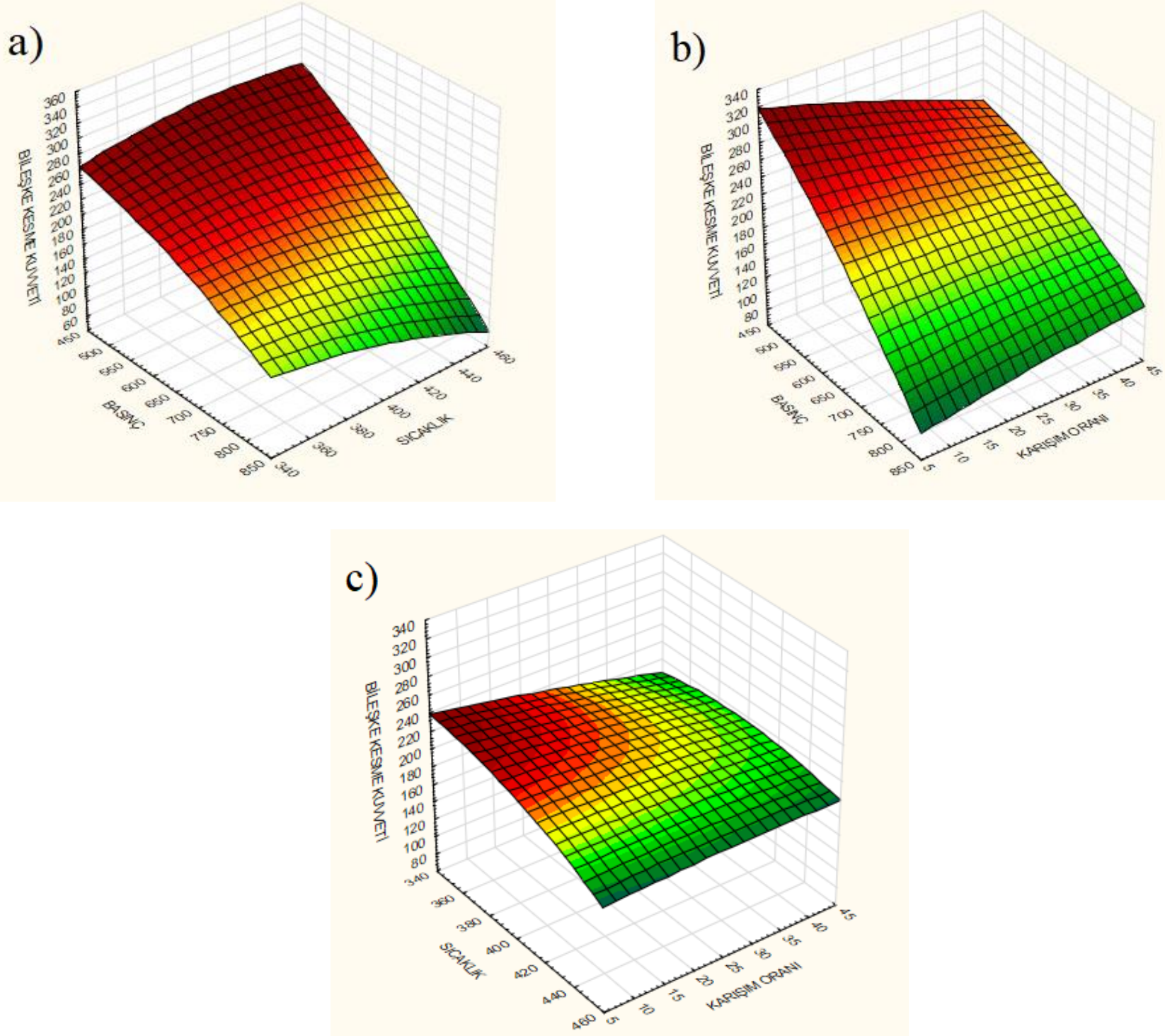

Şekil 2. Farklı üretim şartları kombinasyonlarında bileşke kesme kuvveti değişimi a) Basınç-Sıcaklık, b) Basınç-Karışım Oranı, c) Sıcaklık-Karışım Oranı

Tablo 4, sinyal-gürültü oranına göre bileşke kesme kuvveti için varyans analizi sonuçlarını göstermektedir. Her bir bağımsız değişkene ait kareler toplamı değerinin toplam değere bölünmesi ile bulunan katkı oranı ve F-değeri sonuçlarına göre basınç, bileşke kesme kuvveti üzerinde en etkili parametre olarak bulunmuştur (80\%). Basıncı takiben sıcaklık $(5 \%)$ ve karışım oranı $(0,003)$ kuvvet üzerinde oldukça düşük etkiye sahip olarak bulunmuştur. Taguchi bazlı varyans analizinin sonuçları yeterli güvenilirlikte bulunmuştur $(\mathrm{R}-\mathrm{Sq}=86,7 \%$ ve $\mathrm{R}-\mathrm{Sq}(\operatorname{adj})=83,3 \%)$. Normal şartlar altında, geleneksel malzemelerin istatistiksel analizlerinde, üretim şartlarının sabit olması ve kompozit malzemelere kıyasla izotropik özellikler göstermesi sebebiyle R-Sq oranları daha yüksek çıkmaktadır. Ancak, kendi içerisinde birçok değişkeni olan (üretim sıcaklığı, basınç, karışım oranı, tane düzensizliği) ve bu değişkenlere bağlı olarak anizotropik özellikler gösteren kompozit malzemelerde \%87 mertebelerinde güvenilirlik oranı elde edilmesi oldukça önemlidir. Dolayısıyla bu istatistiksel yaklaşımın, kompozit malzemeler için etkili bir şekilde kullanılabileceği söylenebilir. 
Tablo 4. Sinyal-gürültü oranına göre bileşke kesme kuvveti için varyans analizi sonuçları

\begin{tabular}{lllllll}
\hline $\begin{array}{l}\text { Bağımsız } \\
\text { Değișkenler }\end{array}$ & SD & $\begin{array}{l}\text { Kareler } \\
\text { Toplamı }\end{array}$ & Ortalamalar & F-Değeri & P-Değeri & $\begin{array}{l}\text { Katkı } \\
\text { Oranı }\end{array}$ \\
\hline Basınç & 2 & 278,989 & 139,495 & 84,59 & 0,000 & $80 \%$ \\
Sıcaklık & 2 & 20,401 & 10,200 & 6,19 & 0,006 & $5 \%$ \\
Karışım Oranı & 3 & 1,036 & 0,345 & 0,21 & 0,889 & $0,3 \%$ \\
Hata & 28 & 46,172 & 1,649 & - & - & $14,7 \%$ \\
Toplam & $\mathbf{3 5}$ & $\mathbf{3 4 6 , 5 9 7}$ & - & - & - & $100 \%$ \\
\hline
\end{tabular}

Tablo 5'te ve Şekil 3'te sinyal-gürültü oranına göre elde edilen sonuçlar bulunmaktadır. Derece ile ifade edilen değerler sırası ile kesme kuvveti üzerindeki en etkili parametreleri ifade etmektedir. Tablo.5' de görüldüğü üzere kesme kuvvetleri üzerinde en etkili parametrenin sırasıyla basınç, sıcaklık ve karışım oranı olduğu tespit edilmiştir. Varyans analizi tablosunda bulunan katkı oranı sonuçları burada da bulunmuş ve basınç, sıcaklık, karışım oranı sıralaması ile değişkenlerin etkinliği doğrulanmıştır. En küçük kesme kuvveti değerini veren değişken seviyeleri ise koyu renkli yazı ile işaretlenmiştir. Buna göre optimum kesme kuvveti basıncın ve sıcaklığın üçüncü derece, karışım oranının birinci değerlerinin seçilmesi ile elde edilmektedir $\left(\mathrm{B} 3=820 \mathrm{MPa}, \mathrm{S} 3=450^{\circ} \mathrm{C}, \mathrm{K} 1=\right.$ ağ. \%10 GGG-40 takviyeli).

Tablo 5. Sinyal-gürültü oranları için elde edilen sonuçlar

\begin{tabular}{lccl}
\hline Seviye & Basınç & Sıcaklık & Karışım Oranı \\
\hline 1 & $-48,57$ & $-46,92$ & $-45,87$ \\
2 & $-46,56$ & $-45,97$ & $-45,83$ \\
3 & $\mathbf{- 4 1 , 9 2}$ & $\mathbf{- 4 4 , 6 5}$ & $\mathbf{- 4 5 , 5 1}$ \\
4 & - & - & $\mathbf{- 4 5 , 5 1}$ \\
$\Delta$ & 6,65 & 1,77 & 2,442 \\
Derece & $\mathbf{1}$ & $\mathbf{2}$ & $\mathbf{3}$ \\
\hline
\end{tabular}

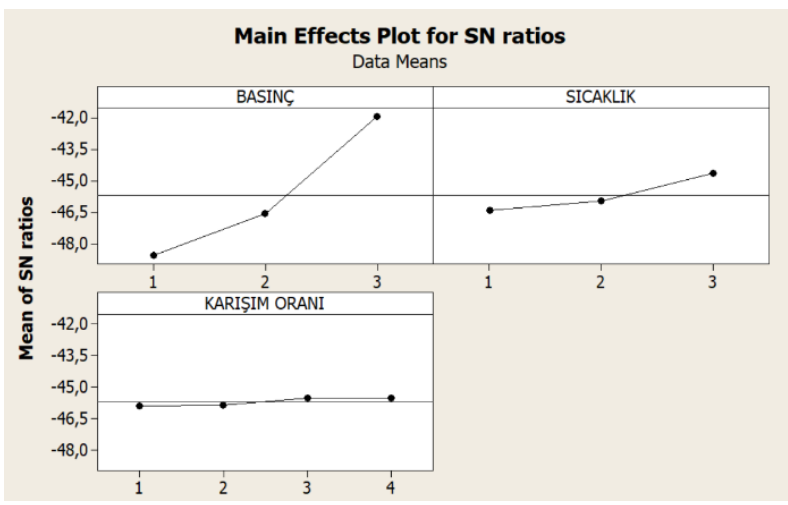

Şekil 3. Sinyal-gürültü oranları için elde edilen sonuçlar

\section{SONUÇLAR}

$\mathrm{Bu}$ çalışmada metal matrisli kompozit malzemelerin işlenebilirliği ve üretim parametrelerinin tornalama esnasında oluşan kesme kuvvetlerine etkisi incelenmiştir. Tüm üretim parametrelerinin kesme kuvvetine etkisi istatistiksel bir yaklaşımla incelenerek birbirinden bağımsız bir şekilde etki oranları belirlenmiştir. Elde edilen sonuçlar aşağıda siralanmaktadır.

$>\mathrm{S} / \mathrm{N}$ oranları kullanılarak kesme kuvvetlerini en aza indirmek için kontrol faktörlerinin optimum seviyeleri belirlenmiştir. Kesme kuvveti için optimum durumlar üretim basıncı olarak $\mathrm{B}_{3}=820 \mathrm{MPa}$, üretim sicaklığı olarak $\mathrm{S}_{3}=450^{\circ} \mathrm{C}$, katk1 oranı olarak ise $\mathrm{K}_{1}=$ ağ. $\% 10 \quad$ GGG-40 takviyeli şeklinde belirlenmiştir.

> Yapılan istatiksel analizlerin sonucuna bakılarak sıcak presleme yöntemi ile üretilen metal matrisli kompozit malzemelerin bileşke kesme kuvveti üzerine en çok etkisi olan parametrenin $\% 80$ katkı oranıyla birlikte üretim basıncı olduğu tespit edilmiştir. Tornalama sırasında oluşan bileşke kuvvetler üzerinde sıcaklık ve katkı oranının etkisinin basınca göre çok az olduğu gözlemlenmiştir.

- Yapılan istatistiksel yaklaşımın güvenilirlik oranı $\% 86,7$ olarak tespit edilmiş ki bu da uygulanan modelin kompozit malzemeler için etkili bir şekilde kullanılabileceğinin göstergesidir.

$>$ Tornalama esnasinda (üretimden kaynaklanan bazı istisnai durumlar dışında) genel olarak en düşük bileşke kuvvetler, üretim basıncının en yüksek olduğu değerlerde gözlemlenmiştir. $\mathrm{Bu}$ durum, yüksek basınç değerlerine çıkıldığında, metalik talaşların yumuşayarak birbirlerini daha iyi kaplaması ve daha iyi yapısal bütünlük sağlamasına bağlı olarak numunelerin işlenebilirliğinin artmasından kaynaklanmaktadır. 


\section{KAYNAKÇA}

[1] H. Sepet, N. Tarakcioglu, and R. Misra, "Determination of the mechanical, thermal and physical properties of nano-CaCO3 filled high-density polyethylene nanocomposites produced in an industrial scale," J Compos Mater, vol. 50, no. 24, pp. 3445-3456, 2016.

[2] H. Sepet, B. Aydemir, and N. Tarakcioglu, "Evaluation of mechanical and thermal properties and creep behavior of micro-and nano-CaCO 3 particle-filled HDPE nano-and microcomposites produced in large scale," Polymer Bulletin, pp. 1-19, 2019.

[3] A. Aslan, O. S. Sahin, E. Salur, A. Gunes, A. Akdemir, and H. B. Karadag, "A new method for recycling of metal chips," Journal of Selçuk University Natural and Applied Science, vol. 4, no. 1, pp. 1-12, 2015.

[4] A. Aslan, E. Salur, A. Gunes, O. Sahin, H. Karadag, and A. Akdemir, "The mechanical properties of composite materials recycled from waste metallic chips under different pressures," International Journal of Environmental Science and Technology, pp. 1-8, 2019.

[5] K. K. Chawla, "Metal matrix composites," Mater Sci Tech-Lond, 2006.

[6] S. R. Bakshi, D. Lahiri, and A. Agarwal, "Carbon nanotube reinforced metal matrix composites-a review," International materials reviews, vol. 55, no. 1, pp. 41-64, 2010 .

[7] J. Kaczmar, K. Pietrzak, and W. Włosiński, "The production and application of metal matrix composite materials," Journal of materials processing technology, vol. 106, no. 1-3, pp. 58-67, 2000.

[8] H. Kwon, M. Estili, K. Takagi, T. Miyazaki, and A. Kawasaki, "Combination of hot extrusion and spark plasma sintering for producing carbon nanotube reinforced aluminum matrix composites," Carbon, vol. 47, no. 3, pp. 570-577, 2009.

[9] J. Fogagnolo, E. Ruiz-Navas, M. Simón, and M. Martinez, "Recycling of aluminium alloy and aluminium matrix composite chips by pressing and hot extrusion," Journal of Materials Processing Technology, vol. 143, pp. 792-795, 2003.

[10] F. Tang, I. E. Anderson, T. Gnaupel-Herold, and H. Prask, "Pure Al matrix composites produced by vacuum hot pressing: tensile properties and strengthening mechanisms," Materials Science and Engineering: A, vol. 383, no. 2, pp. 362-373, 2004.

[11] A. Aslan, E. Salur, A. Güneş, Ö. S. Şahin, H. B. Karadağ, and A. Akdemir, "Production and mechanical characterization of prismatic shape machine element by recycling of bronze and cast-iron chips," J Facul Eng Archit Gazi Univ, vol. 33, no. 3, pp. 1013-1027, 2018.

[12] I. Sabirov, O. Kolednik, and R. Pippan, "Homogenization of metal matrix composites by highpressure torsion," Metallurgical and Materials Transactions A, vol. 36, no. 10, pp. 2861-2870, 2005.

[13] S. C. Tjong and Z. Ma, "Microstructural and mechanical characteristics of in situ metal matrix composites," Materials Science and Engineering: R: Reports, vol. 29, no. 3-4, pp. 49-113, 2000.
[14] A. Aslan, "Production of metal matrix composites by recycling of waste metal chips and their mechanical properties," Ms Thesis, Selçuk University, Department of Mechanical Engineering, Konya, 2014.

[15] S. Lo, S. Dionne, M. Sahoo, and H. Hawthorne, "Mechanical and tribological properties of zinc-aluminium metal-matrix composites," J Mater Sci, vol. 27, no. 21, pp. 5681-5691, 1992.

[16] J. Gronostajski, J. Kaczmar, H. Marciniak, and A. Matuszak, "Direct recycling of aluminium chips into extruded products," Journal of Materials Processing Technology, vol. 64, no. 1-3, pp. 149-156, 1997.

[17] J. Gronostajski, H. Marciniak, and A. Matuszak, "New methods of aluminium and aluminium-alloy chips recycling," Journal of materials processing technology, vol. 106, no. 1-3, pp. 34-39, 2000.

[18] Y. Tao, M.-Y. Zheng, X.-S. Hu, and W. Kun, "Recycling of AZ91 Mg alloy through consolidation of machined chips by extrusion and ECAP," T Nonferr Metal Soc, vol. 20, pp. s604-s607, 2010.

[19] Ö. S. Şahin, A. Güneş, A. Aslan, E. Salur, H. B. Karadağ, and A. Akdemir, "Low-velocity impact behavior of porous metal matrix composites produced by recycling of bronze and iron chips," Iranian Journal of Science and Technology, Transactions of Mechanical Engineering, pp. 18, 2017.

[20] E. Salur, "Investigation of machinability properties of metal matrix composites produced by recycling of waste metal chips," Ms thesis, Selçuk University, Department of Mechanical Engineering, Konya, 2017.

[21] E. Salur, A. Aslan, M. Kuntoglu, A. Gunes, and O. S. Sahin, "Experimental study and analysis of machinability characteristics of metal matrix composites during drilling," Composites Part B: Engineering, vol. 166, pp. 401-413, 2019.

[22] Ş. Karabulut and H. Karakoç, "Investigation of surface roughness in the milling of Al7075 and open-cell SiC foam composite and optimization of machining parameters," Neural Computing and Applications, vol. 28, no. 2, pp. 313327, 2017.

[23] S. A. Niknam, S. Kamalizadeh, A. Asgari, and M. Balazinski, "Turning titanium metal matrix composites (TiMMCs) with carbide and CBN inserts," The International Journal of Advanced Manufacturing Technology, vol. 97, no. 1-4, pp. 253-265, 2018.

[24] M. M. Barzani, S. Farahany, and V. Songmene, "Machinability characteristics, thermal and mechanical properties of Al-Mg2Si in-situ composite with bismuth," Measurement, vol. 110, pp. 263-274, 2017.

[25] J. d. Torralba, C. Da Costa, and F. Velasco, "P/M aluminum matrix composites: an overview," Journal of Materials Processing Technology, vol. 133, no. 1-2, pp. 203206, 2003.

[26] R. N. Rai, G. Datta, M. Chakraborty, and A. Chattopadhyay, "A study on the machinability behaviour of Al-TiC composite prepared by in situ technique," Materials Science and Engineering: A, vol. 428, no. 1-2, pp. 34-40, 2006. 
[27] K. Abdullah, S. SÜRÜCÜLER, and A. KİRİ, "Kesme Kuvvetlerinin Tahmini İçin Matematiksel Bir Model Geliştirme," Politeknik Dergisi, vol. 13, no. 1, pp. 1520, 2010.

[28] D. S. C. Kishore, K. P. Rao, and A. Ramesh, "Optimization of machining parameters for improving cutting force and surface roughness in turning of Al6061TiC in-situ metal matrix composites by using Taguchi method," Materials Today: Proceedings, vol. 2, no. 4-5, pp. 3075-3083, 2015.

[29] I. Hanafi, A. Khamlichi, F. M. Cabrera, P. J. N. López, and A. Jabbouri, "Fuzzy rule based predictive model for cutting force in turning of reinforced PEEK composite," Measurement, vol. 45, no. 6, pp. 1424-1435, 2012.

[30] A. Salımıasl and M. Rafıghı, "Titreşim ve Kesme Kuvveti Esaslı Takım Aşınmasının Bulanık Mantıkla İzlenmesi ve Tahmini," Politeknik Dergisi, vol. 20, no. 1, pp. 111-120, 2017.

[31] M. Kuntoğlu and H. Sağlam, "Investigation of progressive tool wear for determining of optimized machining parameters in turning," Measurement, vol. 140, pp. 427-436, 2019.

[32] C. Fetecau and F. Stan, "Study of cutting force and surface roughness in the turning of polytetrafluoroethylene composites with a polycrystalline diamond tool," Measurement, vol. 45, no. 6, pp. 1367-1379, 2012.

[33] D. S. C. Kishore, K. P. Rao, and A. Mahamani, "Investigation of cutting force, surface roughness and flank wear in turning of In-situ Al6061-TiC metal matrix composite," Procedia materials science, vol. 6, pp. 1040-
1050, 2014.

[34] Ş. Karabulut, "Optimization of surface roughness and cutting force during AA7039/A12O3 metal matrix composites milling using neural networks and Taguchi method," Measurement, vol. 66, pp. 139-149, 2015.

[35] A. Pugazhenthi, G. Kanagaraj, I. Dinaharan, and J. D. R. Selvam, "Turning characteristics of in situ formed TiB2 ceramic particulate reinforced AA7075 aluminum matrix composites using polycrystalline diamond cutting tool," Measurement, vol. 121, pp. 39-46, 2018.

[36] A. Razavykia, S. Farahany, and N. M. Yusof, "Evaluation of cutting force and surface roughness in the dry turning of $\mathrm{Al}-\mathrm{Mg} 2 \mathrm{Si}$ in-situ metal matrix composite inoculated with bismuth using DOE approach," Measurement, vol. 76, pp. 170-182, 2015.

[37] C. Shoba, N. Ramanaiah, and D. N. Rao, "Effect of reinforcement on the cutting forces while machining metal matrix composites-an experimental approach," Engineering Science and Technology, an International Journal, vol. 18, no. 4, pp. 658-663, 2015.

[38] D. Srinivas, R. Kadadevaramath, B. L. Shankar, P. Nagraj, J. Bhaskaran, and D. Mallapur, "Optimization of Machinability Parameters of Al1100-B4C Composites using Taguchi Method," Materials Today: Proceedings, vol. 4, no. 10, pp. 11305-11313, 2017.

[39] A. Aslan, A. Güneş, E. Salur, Ö. S. Şahin, H. B. Karadağ, and A. Akdemir, "Mechanical properties and microstructure of composites produced by recycling metal chips," International Journal of Minerals, Metallurgy, and Materials, vol. 25, no. 9, pp. 1070-1079, 2018. 